\title{
Evaluating Cost and Time Performance of Sri Lankan Construction Projects
}

\author{
Asitha Rathnayake and Malik Ranasinghe
}

\begin{abstract}
Cost overruns and schedule delays are two of the common issues facing the Sri Lankan construction industry. Hence, managing these aspects of performance, i.e., cost and time predictability, is of high importance. Performance measurement is considered by many to be the first step of performance management. While much of the global and some of the local research work have focused on developing tools or indicators for performance measurement, not many studies have been done on developing methodologies to interpret their results. In this study, suitable key performance indicators were identified from the literature review, and performance benchmarks for these KPIs applicable to the local construction industry were developed using data from twelve recently completed projects. Thereby, five levels of performance from 'Unsatisfactory' to 'Excellent' and corresponding scores from 0-10 were defined. These KPIs were applied to two ongoing projects for a period of 8-9 months which helped not only to demonstrate the use of the performance indicators and intervals, but also to discover a few performance issues present and the reasons. It is expected that the tools developed in this paper will help elevate the levels of performance of construction projects in the country by facilitating continuous measurement and evaluation.
\end{abstract}

Keywords: Cost performance, Time performance, Benchmark, Project performance, Construction project

\section{Introduction}

According to Project Management Institute, a project is a temporary endeavour undertaken to create a unique product, service or result [1]. Construction industry which is composed of many projects has played a vital role in Sri Lanka's economy for a long period, making a contribution of $7.7 \%$ to the Gross Domestic Product in 2017 [2].

A recent study found that senior management of the country's construction companies, on average, gives a priority of $51 \%$ to the areas of cost and time of building construction projects when compared to a set of other areas [3]. Yet, the industry is plagued by cost overruns [4] and schedule delays [5].

The popular expression "if you cannot measure it, you cannot manage it" [6] provides an entrance to this problem. Performance Measurement (PM) has been defined in [7] as "the process of quantifying the efficiency and effectiveness of actions".

The aim of this paper is to device methodologies to interpret and apply suitable indicators to evaluate the cost and time performance of Sri Lankan construction projects, i.e., the predictability of cost and time in construction projects. Under this, the objectives include 1. Understanding indicators used to measure cost and time performance; 2 . Defining levels of performance of identified indicators applicable to the local industry; and 3. Demonstrating the application of the identified indicators and the defined levels of performance. The scope was limited to building construction projects due to different constraints.

The paper is structured as follows. The next section will describe the literature review on indicators of cost and time performance. The third section will describe the research methodology. Sections four and five will describe the development and application of the benchmarks respectively, which will be followed by a discussion of the results, conclusions and recommendations.

\section{Literature Review}

\subsection{Cost Performance}

Cost is defined as "the degree to which the

Eng. Asitha Rathnayake, AMIE (SL), B.Sc.Eng. Hons (UoM), CIMA Dip MA, is a Civil Engineer at Sathuta Builders (Pvt) Ltd.

Email:asithagbr@gmail.com

(10) https://orcid.org/0000-0002-1389-7801

Eng. (Prof.) Malik Ranasinghe, Int PE (SL), CEng, FIE (SL), B.Sc.Eng. Hons (UoM), M.A.Sc (UBC), Ph.D (UBC), FNAS (SL), FIPM (SL), is a Senior Professor of Civil Engineering at University of Moratuwa

Email:malikr.uom@gmail.com

(iD https://orcid.org/0000-0002-6991-1756 
project within the estimated budget" [8]. Cost should address variations, modifications and legal claims in addition to the tender sum [9].

There are many key performance indicators (KPIs) developed by researchers to measure cost predictability, one such indicator is Percentage net variation over final cost (percent NETVAR) [10], which is given in equation 1.

Percent NETVAR $=\frac{\text { Net value of variations }}{\text { Final contract } \text { sum }} \times 100 \%$

Where,

Net value of variations $=$ Final contract sum - Base

Base $=$ Original contract sum + Final rise and fall Contingency allowance

A separate research [11] defines construction cost variance as given in equation 2 .

Percentage $(\%)$ of construction cost variance $=$ $\underline{\text { Actual construction cost - Estimated construction cost }} \times 100 \%$ Estimated construction cost

\subsection{Time Performance}

Time or schedule is defined as "the degree to which the general conditions promote the completion of a project within the allocated time duration" [8]. Scheduling is needed to enable the building to be used by a date determined by the client's future plans [12].

There are numerous KPIs developed by researchers to measure time predictability. One such indicator is Time variation [9], which is given in equation 3 .

Time variation $=\frac{\text { Construction time }- \text { Revised contract period }}{\text { Revised contract period }} \times 100 \%$

Where,

Construction time $=$ Absolute time calculated as the number of days/weeks from start on site to practical completion

Revised contract period $=$ Original contract period + Extension of time granted by the client

Another research [11] defines construction time variance as given by equation 4 .

$\%$ of construction time variance $=$

Discounted construction time $\times 100 \%$

Revised construction time
Where,

Discounted construction time $=$ Actual construction time - Revised construction duration

Revised construction time $=$ Original construction duration (recorded in contract) + Extension of time (granted by the owner)

\subsection{Earned Value Management}

The actual cost incurred in a project can be less than budgeted as at a particular point in time due to using fewer funds to complete the same amount of work. However, incurred cost can also be lower than planned if some work items in the plan were not completed, e.g., due to a delay. Therefore, traditional cost analysis which compares actual cost to budgeted cost is inconclusive. Earned Value Management provides a solution to this issue [13].

Project Management Institute defines Earned Value Management as "a methodology that combines scope, schedule, and resource measurements to assess project performance and progress". Three main concepts are considered. They are: Planned Value $(P V)$ which is the authorized budget assigned to scheduled work, Earned Value $(E V)$ which is a measure of work performed expressed in terms of the budget authorized for that work and Actual Cost $(A C)$ which is the realized cost incurred for the work performed on an activity during a specific time period [1] (refer Figure 1).

Cost and Schedule variances are computed separately as the differences between $E V, A C$ and $P V, E V$, respectively. Cost Performance Index $(C P I)$ and Schedule Performance Index $(S P I)$ as defined in equations 5 and 6 consider these parameters as ratios and are measures of cost and schedule efficiency, respectively [1].

$C P I=\frac{E V}{A C}$

$S P I=\frac{E V}{P V}$

At project completion, schedule variance and SPI converge to 0 and 1 , respectively. This is because no further expenses are to be incurred at this point. However, there can still be a physical delay in progress. Therefore, a study [14] has introduced the concept of Earned Schedule $(E S)$ which identifies when the amount of $E V$ accrued should have occurred. Here, schedule efficiency is calculated comparing with Actual Time $(A T)$ and the 
indicator of 'Schedule Performance Index with respect to Time', SPI ( $t)$ as defined in equation 7 is obtained (refer Figure 2).

$S P I(t)=\frac{E S}{A T}$

\subsection{Sri Lankan Context}

Performance measurement frameworks (PMFs) to measure performance of Sri Lankan construction projects on a continuous basis are rare in literature. Only a previous study done by the authors [3] presents such a PMF with KPIs for cost and time performance. These were the same ones defined in equations 5-7.

Nevertheless, a methodology to interpret and apply the KPIs has not been given. Hence, a literature gap was identified for a methodology to interpret and apply KPIs related to cost and time performance for Sri Lankan construction projects.

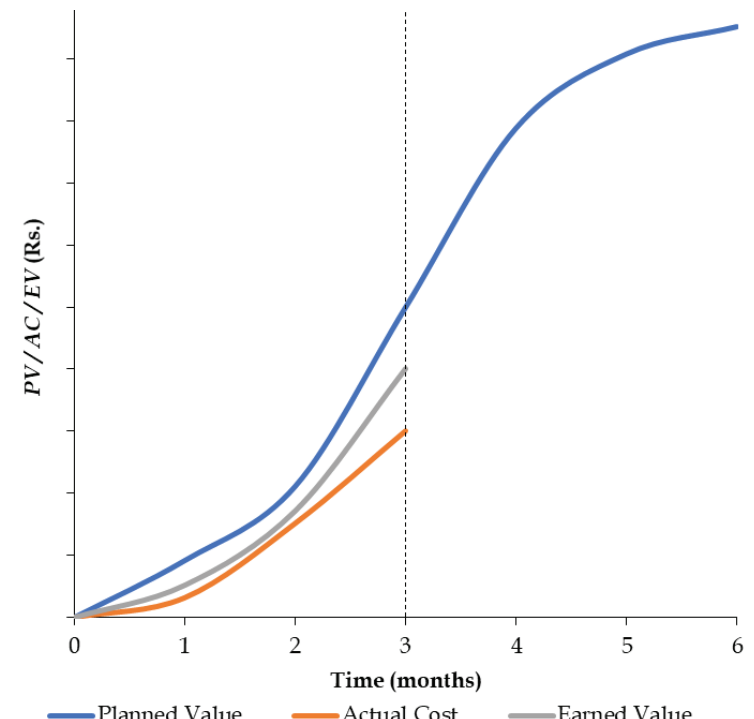

Figure 1 - Cost Analysis with EV Concept [15]

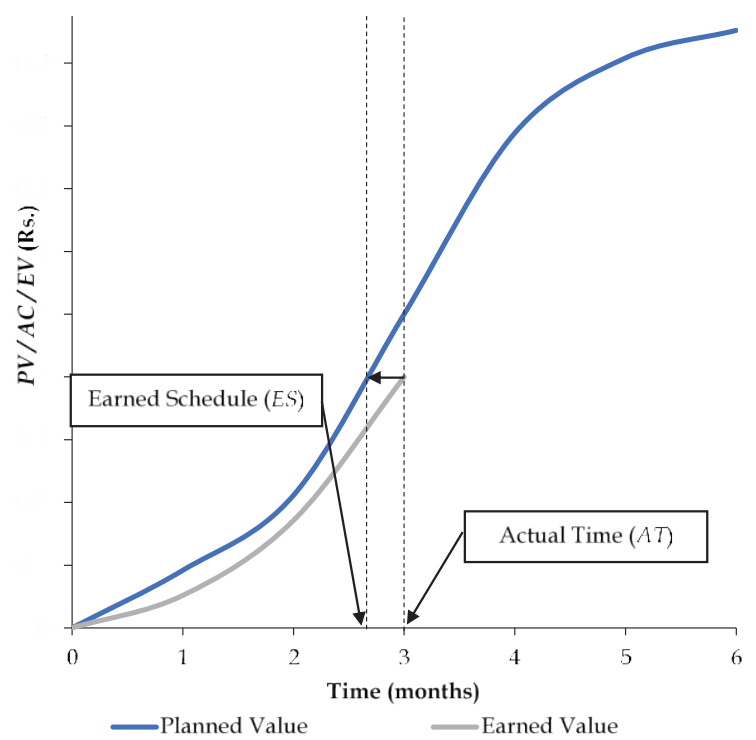

Figure 2 - Earned Schedule [15]

\section{Research Methodology}

The research methodology involved two main stages which are described in the following sections.

\subsection{Interpretation of the Results}

Interpretation of the indicators was done through benchmarking. One study [16] defines benchmarking as "the continuous process of measuring products, services and practices against the toughest competitors or those companies recognized as industry leaders" while another research paper [17] provides a simpler definition, which states that benchmarking is "the technique of evaluating performance in specific areas when compared to recognized leaders".

However, in this paper, benchmarking was defined according to Hudson (1997) [18], that it is "a systematic process of measuring one's performance against results from recognized leaders for the purpose of determining best practices that lead to superior performance when adapted and implemented". This is also the definition adopted by US Construction Industry Institute (CII). Benchmarking can be used by firms to identify industry leaders and adjust their practices to become more similar to those well performing companies [19].

In this study, recognized leaders were assumed as "CIDA CS2 grade companies with CS2 grade for building construction". CS2 grade is the highest level achievable in the Sri Lankan construction industry [20]. CIDA website identifies eight such contractors.

In order to develop benchmarks, six categories of data from recently completed projects (within five years) by these 'recognized leaders' were requested. The categories were: 1 . Contract Sum; 2. Project Duration; 3. Budgeted Cost of the project; 4. Actual Cost incurred at the end; 5. Planned duration for the project; and 6. Actual duration and any extensions of time granted.

Due to confidentiality issues, only the data relating to twelve projects by three companies could be collected as given in Table 1 . 
Table 1 - Projects Used to Collect Data for Benchmarking

\begin{tabular}{|c|c|c|}
\hline $\begin{array}{c}\text { Company name used in } \\
\text { this paper }\end{array}$ & $\begin{array}{c}\text { Project name used in } \\
\text { this paper }\end{array}$ & Project description \\
\hline \multirow[t]{5}{*}{ Company 1} & Project 1 & Mixed-use development project \\
\hline & Project 2 & Club house \\
\hline & Project 3 & Buildings for a higher education institute \\
\hline & Project 4 & Luxury hotel \\
\hline & Project 5 & Mixed-use development project \\
\hline \multirow[t]{5}{*}{ Company 2} & Project 6 & Low income housing project \\
\hline & Project 7 & Buildings for a higher education institute \\
\hline & Project 8 & Buildings for a higher education institute \\
\hline & Project 9 & Buildings for a higher education institute \\
\hline & Project 10 & Buildings for a higher education institute \\
\hline \multirow[t]{2}{*}{ Company 3} & Project 11 & Low income housing project \\
\hline & Project 12 & Low income housing project \\
\hline
\end{tabular}

\subsection{Application of the Results}

Two recently commenced projects of Company 2 were selected and the KPIs were calculated monthly. Both the projects were buildings for higher education institutes. They are denoted in this paper as: Project A and Project B.

The purpose was to check whether the reasons for positive and negative results could be accurately identified.

\section{Developing Benchmarks}

The CPI and SPI ( $t$ ) were calculated using the data from completed projects. The results are given in Table 2.

As mentioned in section 2.3, SPI of completed projects invariably becomes 1 . Hence, only SPI $(t)$ can be calculated. SPI ( $t$ ) was analysed with and without the extensions of time (EOT) granted.

Note that a majority of projects had delays which had been granted extensions of time. Since granting EOTs avoids the financial implications such as liquidated damages to be paid by the contractors, data of SPI $(t)$ with EOT (actual values) were used to establish the benchmarks for the financial indicator of time predictability, i.e., SPI. On the other hand, since the additional time elapsed cannot be recovered whether an EOT is granted or not, data of SPI (t) without EOT were used to establish the benchmarks for the physical indicator of time predictability, i.e., SPI ( $t$ ). The statistics used to establish the benchmarks are given in Table 3.

Two approaches were taken to develop benchmarks, which are described in sections 4.1 and 4.2 .

\subsection{Arbitrary Method}

Five intervals or levels of performance identified in previous literature [21] were adapted to group scores for the three indicators. They were: Unsatisfactory (US), Improvement Needed $(I N)$, Average $(A V)$, Above Average $(A A)$ and Excellent $(E X)$.

Table 2 - CPI and SPI ( $t$ ) Data of Completed Projects

\begin{tabular}{|c|c|c|c|c|}
\hline & $\begin{array}{l}\text { Project } \\
\text { Number }\end{array}$ & $\begin{array}{l}C P I \\
\text { at } \\
\text { the } \\
\text { end }\end{array}$ & $\begin{array}{c}S P I(t) \text { at } \\
\text { the end - } \\
\text { without } \\
\text { EOT }\end{array}$ & $\begin{array}{l}S P I(t) \\
\text { at the } \\
\text { end - } \\
\text { actual }\end{array}$ \\
\hline \multirow{5}{*}{ 苞 } & 1 & 1.005 & 0.818 & 0.818 \\
\hline & 2 & 1.016 & 0.857 & 0.857 \\
\hline & 3 & 0.956 & 0.825 & 0.825 \\
\hline & 4 & 1.099 & 0.615 & 1 \\
\hline & 5 & 0.847 & 0.677 & 1 \\
\hline \multirow{5}{*}{ 莡 } & 6 & 0.852 & 0.520 & 1 \\
\hline & 7 & 1.004 & 0.978 & 1 \\
\hline & 8 & 0.845 & 0.888 & 1 \\
\hline & 9 & 1.017 & 0.888 & 1 \\
\hline & 10 & 0.850 & 0.943 & 1 \\
\hline \multirow{2}{*}{ : } & 11 & 1.024 & 0.857 & 1 \\
\hline & 12 & 0.938 & 0.682 & 1 \\
\hline \multicolumn{2}{|c|}{ Mean } & 0.954 & 0.796 & 0.958 \\
\hline \multicolumn{2}{|c|}{$\begin{array}{l}\text { Standard } \\
\text { Deviation }\end{array}$} & 0.087 & 0.140 & 0.076 \\
\hline
\end{tabular}

Table 3 - Statistics Used to Establish Benchmarks for CPI, SPI and SPI $(t)$

\begin{tabular}{|l|c|c|c|}
\hline & CPI & SPI & SPI $(\boldsymbol{t})$ \\
\hline Mean & 0.954 & 0.958 & 0.796 \\
\hline Standard Deviation & 0.087 & 0.076 & 0.140 \\
\hline
\end{tabular}


The mean was given a score of 5 and was assigned as the median value of 'Average' interval. On budget or on schedule performance $(C P I, S P I$ or $S P I(t)=1)$ was given a score of 8 and assigned as the median value of 'Above Average' interval. The value difference between these 2 medians was taken as the width of the intervals. Hence, the intervals given in Table 4 were defined.

A higher concentration of scores in the middle interval was because most projects perform in that region. Using this approach, the CPI, SPI and SPI $(t)$ values are interpolated to obtain the scores as necessary.

\subsection{Statistical Method}

It has been found that quantitative measure values such as CPI and SPI follow the normal distribution [21]. Hence, in this method, levels of performance were defined by considering the confidence intervals. Since the sample sizes were small, $t$-distributions were used to estimate the population distributions. Standardization was done to relate probabilities. Since two parameters, population mean and population standard deviation, were estimated in each case, the number of degrees of freedom of the t-distribution (df) was taken following equation 8 [22].

$d f=n-N_{e}$

Where,

$n=$ Sample size

$N_{e}=$ No. of parameters estimated

$d f=12-2=10$

The $t$-scores were calculated following equation 9 [22].

$t=\frac{x-\bar{x}}{s}$

Table 4 - Ranges of Scores for CPI, SPI and SPI $(t)$

\begin{tabular}{|c|c|c|c|c|c|}
\hline Interval & US & $I N$ & $A V$ & $A A$ & $E X$ \\
\hline Score & 0 & $1-3$ & $3-7$ & $7-9$ & 10 \\
\hline$C P I$ & $\begin{array}{l}<0.87 \\
5\end{array}$ & $\begin{array}{l}0.875- \\
0.925\end{array}$ & $\begin{array}{l}0.925- \\
0.975\end{array}$ & $\begin{array}{l}0.975- \\
1.025\end{array}$ & $\begin{array}{l}1.025 \\
<\end{array}$ \\
\hline SPI & $<0.90$ & $\begin{array}{l}0.90- \\
0.94\end{array}$ & $\begin{array}{l}0.94- \\
0.98\end{array}$ & $\begin{array}{l}0.98- \\
1.02\end{array}$ & $\begin{array}{l}1.02 \\
<\end{array}$ \\
\hline$S P I(t)$ & $<0.50$ & $\begin{array}{l}0.50- \\
0.70\end{array}$ & $\begin{array}{l}0.70- \\
0.90\end{array}$ & $\begin{array}{l}0.90- \\
1.10\end{array}$ & $\begin{array}{l}1.10 \\
<\end{array}$ \\
\hline
\end{tabular}

Where,

$$
\begin{aligned}
& t=t-\text { score } \\
& x=\text { Raw score }(\mathrm{CPI} / \mathrm{SPI} / \mathrm{SPI}(\mathrm{t}) \text { value }) \\
& \bar{x}=\text { Sample mean } \\
& s=\text { Sample standard deviation }
\end{aligned}
$$

The same five intervals as in section 4.1, Unsatisfactory (US), Improvement Needed $(I N)$, Average $(A V)$, Above Average $(A A)$ and Excellent (EX), were established. In this approach, they were defined to have equal probabilities, i.e., equal areas under the probability density curve. The intervals have been represented graphically using Minitab 19 software in Figure 3.

Each interval was further divided into two equal sub intervals based on probability. Hence, scores from 1-9 were assigned to lefttailed $t$-values (given in red above the distribution in Figure 3) corresponding to significance levels from $0.1-0.9$.

For example, a standardized CPI of 0.541 corresponds to a left-tailed significance level of 0.7, which can be represented as in Figure 4.

Converting this into the raw score $(C P I)$ using equation 9 ,

$$
\begin{aligned}
& 0.541=\frac{x-\bar{x}}{s}=\frac{x-0.954}{0.087} \\
& x=C P I=1.001
\end{aligned}
$$

Hence, a CPI of 1.001 is better than $70 \%$ of the projects in the industry. Therefore, the project is assigned a score of 7 for cost performance.

Similarly, the CPI, SPI and SPI (t) values corresponding to the other scores have been calculated as given in Table 5 . Since the tdistribution is unbounded, scores of 0 and 10 were assigned to cases when left-tailed $t$-value theoretically approaches $-\infty$ and $+\infty$, respectively.

The scores will be calculated as follows. First, CPI, SPI and SPI (t) will be computed. Then, they will be converted to t-scores using equation 9. Next, the corresponding probabilities will be obtained using a left-tailed $\mathrm{t}$-table or the excel function "T.DIST (t-score, 10, TRUE)". Finally, the score will be probability multiplied by 10 . Since a more methodical approach was taken in section 4.2 and the score derived has a physical meaning (proportion of projects surpassed * 10), it was preferred over the one in section 4.1. 


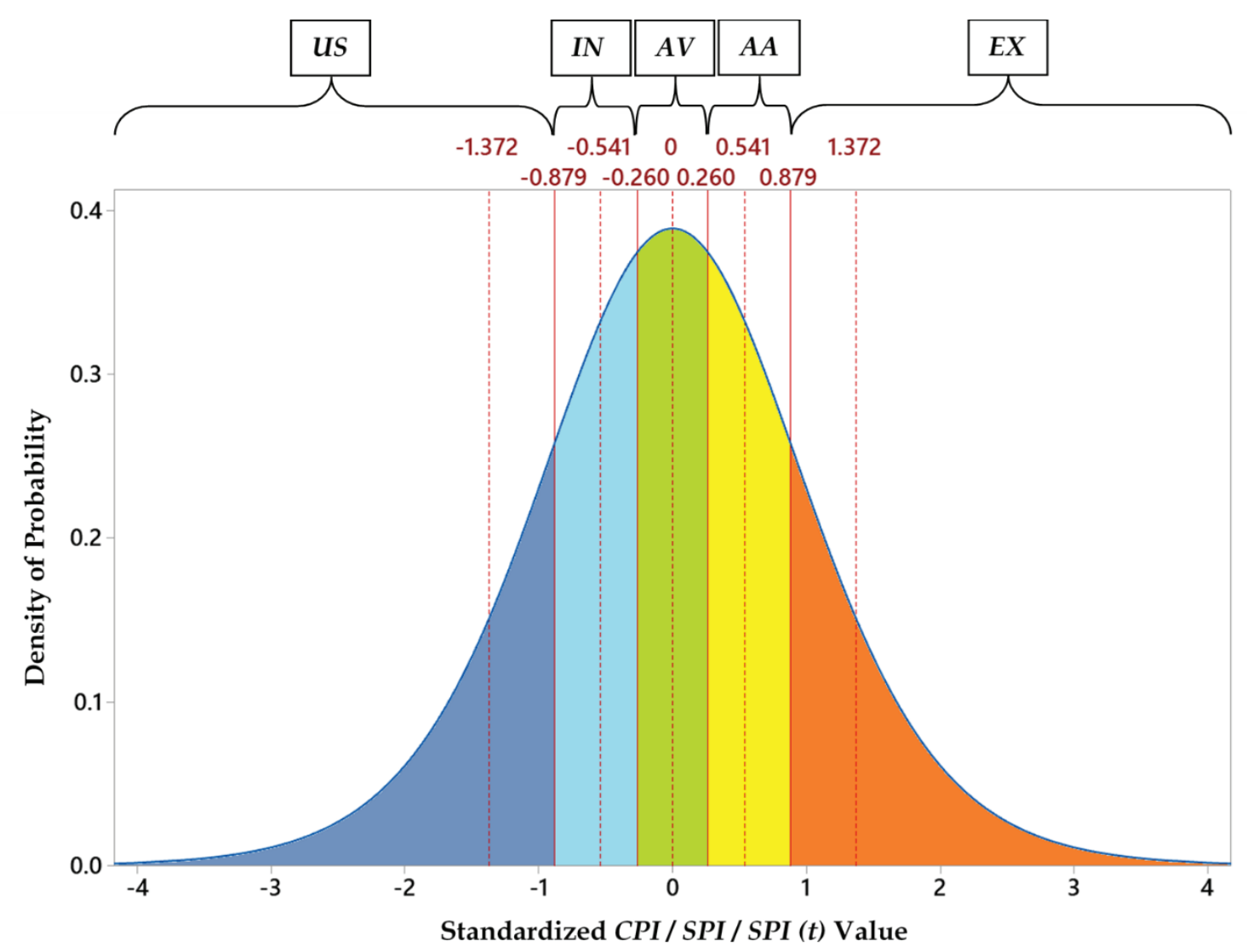

Figure 3 - Intervals Defined for Standardized CPI, SPI and SPI $(t)$

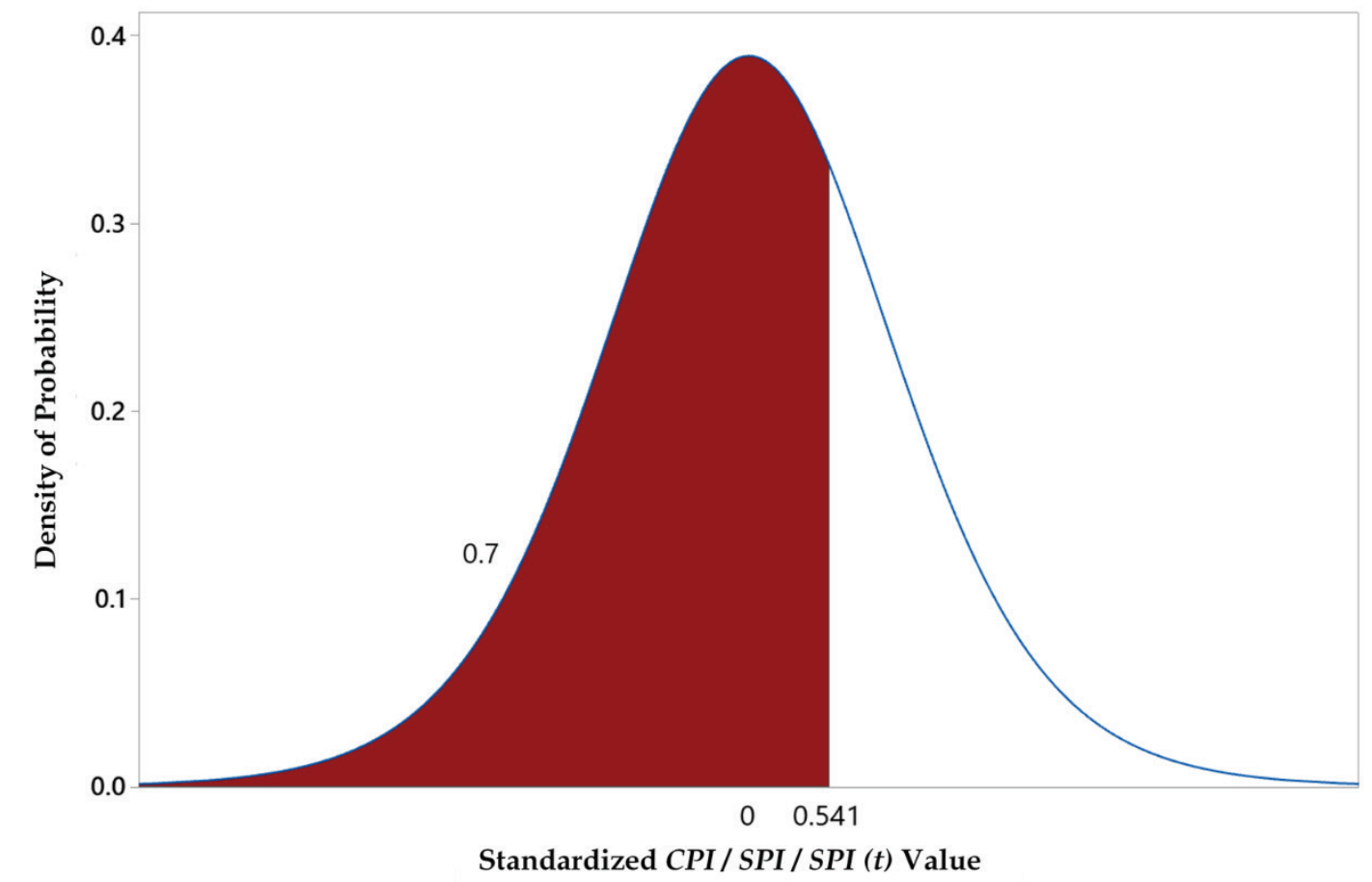

Figure 4 - Left-Tailed T-Value Corresponding to a Significance Level of 0.7

Table 5 - CPI, SPI, SPI ( $t$ ) Values Corresponding to Different Scores

\begin{tabular}{|c|c|c|c|c|c|c|c|c|c|c|c|}
\hline Interval & \multicolumn{3}{|c|}{ US } & \multicolumn{2}{|l|}{$I N$} & \multicolumn{2}{|l|}{$A V$} & \multicolumn{2}{|l|}{$A A$} & \multicolumn{2}{|l|}{$E X$} \\
\hline Score & 0 & 1 & 2 & 3 & 4 & 5 & 6 & 7 & 8 & 9 & 10 \\
\hline t-score & $-\infty$ & -1.372 & -0.879 & -0.541 & -0.260 & 0 & 0.260 & 0.541 & 0.879 & 1.372 & $+\infty$ \\
\hline$C P I$ & $-\infty$ & 0.835 & 0.878 & 0.907 & 0.931 & 0.954 & 0.977 & 1.001 & 1.030 & 1.073 & $+\infty$ \\
\hline SPI & $-\infty$ & 0.854 & 0.891 & 0.917 & 0.938 & 0.958 & 0.978 & 0.999 & 1.025 & 1.062 & $+\infty$ \\
\hline$S P I(t)$ & $-\infty$ & 0.604 & 0.673 & 0.720 & 0.760 & 0.796 & 0.832 & 0.872 & 0.919 & 0.988 & $+\infty$ \\
\hline
\end{tabular}




\section{Application of the Indicators and Benchmarks}

As mentioned in section 3.2, two recently commenced projects of Company 2 were selected and the KPIs were calculated monthly.

\subsection{Project A - CPI, SPI and SPI $(t)$}

Cumulative $P V, E V$ and $A C$ data of Project $\mathrm{A}$ are given in Table 6. A sample calculation has been done as at the end of June 2019 to better understand the KPIs.

From equation 5 ,

$$
C P I=\frac{E V}{A C}=\frac{21,870,868}{28,248,553}=0.77422 \approx 0.77
$$

From equation 6 ,

$$
S P I=\frac{E V}{P V}=\frac{21,870,868}{39,752,616}=0.55017 \approx 0.55
$$

SPI ( $t$ ) was calculated following the procedure given in [23] (refer Figure 5).

Note that, Performance Measurement Baseline $(\mathrm{PMB})$ is the cumulative $P V$ over time. $C$ is the number of whole time increments of PMB for the condition $E V \geq P V$ and $I$ is the portion of PMB increment earned.

$C=5$ months

$I=\frac{E V-P V_{C}}{P V_{C+1^{-}} P V_{C}}=\frac{E V-P V_{\text {April }}}{P V_{\text {May }}-P V_{\text {April }}}$

$I=\frac{21,870,868-20,600,016}{26,357,052-20,600,016}=0.22074 \approx 0.22$ months

$E S=C+I=5.22$ months

$A T=7$ months

From equation 7,

$\operatorname{SPI}(t)=\frac{E S}{A T}=\frac{5.22}{7}=0.75$

Similarly, the rest of the values have been calculated as given in Table 7.

\subsection{Project B - CPI, SPI and SPI ( $t)$}

The Cumulative $P V, E V$ and $A C$ data and the calculated CPI, SPI and SPI ( $t)$ of Project B are given in Table 8 and Table 9, respectively.

Table 6 - Cumulative PV, EV and AC Data of Project A (Rs.)

\begin{tabular}{|l|l|l|l|l|l|l|l|l|r|}
\hline & Dec-18 & \multicolumn{1}{|c|}{ Jan-19 } & \multicolumn{1}{|c|}{ Feb-19 } & \multicolumn{1}{|c|}{ Mar-19 } & \multicolumn{1}{|c|}{ Apr-19 } & \multicolumn{1}{|c|}{ May-19 } & \multicolumn{1}{|c|}{ Jun-19 } & \multicolumn{1}{|c|}{ Jul-19 } & \multicolumn{1}{|c|}{ Aug-19 } \\
\hline $\boldsymbol{P}$ & $2,545,52$ & $5,624,15$ & $10,807,5$ & $15,001,3$ & $20,600,0$ & $26,357,0$ & $39,752,6$ & $56,811,6$ & $68,936,2$ \\
$\boldsymbol{V}$ & 0 & 0 & 50 & 80 & 16 & 52 & 16 & 25 & 03 \\
\hline $\boldsymbol{E}$ & $1,848,52$ & $4,039,11$ & $8,070,47$ & $10,525,0$ & $12,519,9$ & $17,333,5$ & $21,870,8$ & $28,512,9$ & $53,923,9$ \\
$\boldsymbol{V}$ & 0 & 0 & 0 & 60 & 76 & 92 & 68 & 15 & 10 \\
\hline $\boldsymbol{A}$ & $8,713,07$ & $10,149,4$ & $10,335,5$ & $10,533,6$ & $14,120,0$ & $23,998,9$ & $28,248,5$ & $49,297,8$ & $65,096,2$ \\
$\boldsymbol{C}$ & 4 & 79 & 09 & 95 & 40 & 49 & 53 & 84 & 72 \\
\hline
\end{tabular}

Table 7 - CPI, SPI and SPI $(t)$ of Project A

\begin{tabular}{|l|r|r|r|r|r|r|r|r|r|}
\hline & Dec-18 & Jan-19 & Feb-19 & Mar-19 & Apr-19 & May-19 & Jun-19 & Jul-19 & Aug-19 \\
\hline CPI & 0.21 & 0.40 & 0.78 & 1.00 & 0.89 & 0.72 & 0.77 & 0.58 & 0.83 \\
\hline SPI & 0.73 & 0.72 & 0.75 & 0.70 & 0.61 & 0.66 & 0.55 & 0.50 & 0.78 \\
\hline SPI $(\boldsymbol{t})$ & 0.73 & 0.74 & 0.82 & 0.74 & 0.68 & 0.74 & 0.75 & 0.77 & 0.87 \\
\hline
\end{tabular}

Table 8 - Cumulative $P V, E V$ and $A C$ Data of Project B (Rs.)

\begin{tabular}{|l|r|r|r|r|r|r|r|r|}
\hline & Jan-19 & Feb-19 & Mar-19 & Apr-19 & May-19 & Jun-19 & Jul-19 & Aug-19 \\
\hline $\boldsymbol{P V}$ & $9,788,750$ & $19,196,200$ & $19,835,800$ & $21,383,437$ & $25,472,845$ & $47,354,645$ & $67,436,630$ & $82,991,540$ \\
\hline EV & $8,049,530$ & $13,377,275$ & $16,245,840$ & $19,193,053$ & $24,487,000$ & $32,498,443$ & $43,749,288$ & $49,916,592$ \\
\hline AC & $4,021,233$ & $6,098,658$ & $8,326,392$ & $11,125,670$ & $23,578,172$ & $36,466,253$ & $40,471,949$ & $46,819,229$ \\
\hline
\end{tabular}

Table 9 - CPI, SPI and SPI ( $t)$ of Project B

\begin{tabular}{|l|r|r|r|r|r|r|r|r|}
\hline & Jan-19 & Feb-19 & Mar-19 & Apr-19 & May-19 & Jun-19 & Jul-19 & Aug-19 \\
\hline CPI & 2.00 & 2.19 & 1.95 & 1.73 & 1.04 & 0.89 & 1.08 & 1.07 \\
\hline SPI & 0.82 & 0.70 & 0.82 & 0.90 & 0.96 & 0.69 & 0.65 & 0.60 \\
\hline SPI $(\boldsymbol{t})$ & 0.82 & 0.69 & 0.56 & 0.50 & 0.95 & 0.89 & 0.83 & 0.77 \\
\hline
\end{tabular}




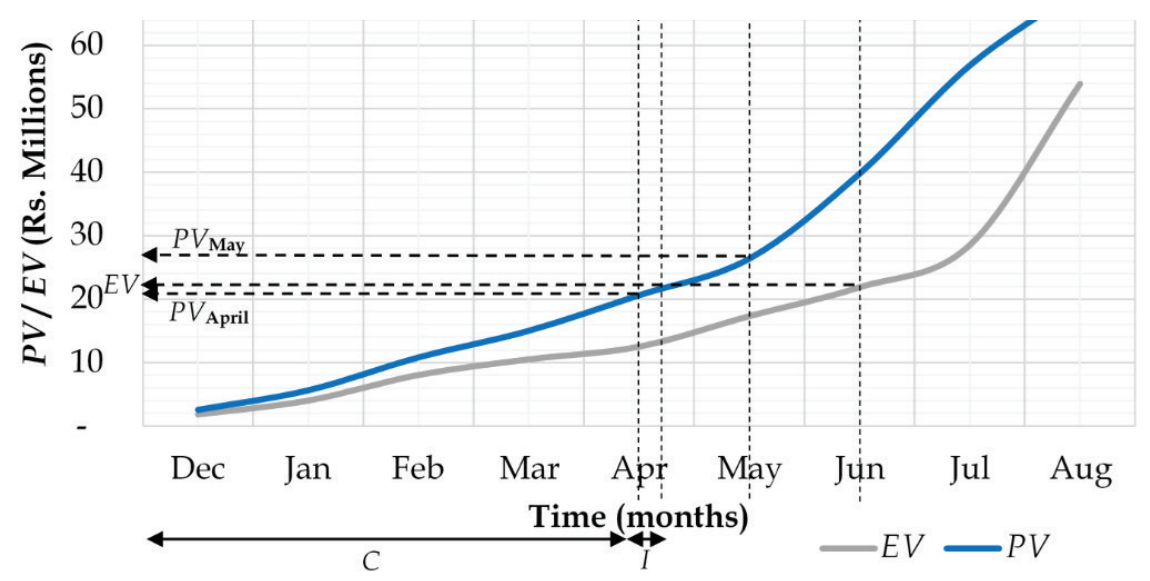

Figure 5 - Sample Calculation of SPI ( $t)$

\section{Discussion of the KPI Results}

The results obtained in section 5 were plotted using Minitab 19 software. As can be seen from Figure 6 - Figure 8, Project B has generally performed better than Project A in the areas of cost and time.

\subsection{Performance with Respect to Cost}

The variations of CPI of the two projects with time are given in Figure 6. Project $\mathrm{B}$ has performed better in terms of cost compared to Project A throughout the months measured.

In the case of Project A, the substructure design had been done considering a soil report provided by the client. In the soil report, only two data points (boreholes) had been considered. The contractor could only perform detailed soil tests after the project was awarded and the land cleared. Then, it was found that a more complex foundation was required (with more retaining walls, fillings, etc.). However, contractually, the contractor had agreed to bear variations due to unforeseen physical conditions. This variation work caused higher expenses than the initial plan.

The relatively high level of performance of Project B was identified to be mainly due to high positive material cost variances and conversely, the relatively low performance of Project A was identified to be mainly due to high negative material cost variances.

Material cost variances had been resulted due to variances in rates and quantities. Since rates are usually dependent on external factors, the authors believe that more priority should be given to quantities. It was identified that the store of Project B was comparatively well managed compared to Project A. Also, the site level wastage was being managed more stringently. This had led to lesser levels of material wastage.

\subsection{Performance with Respect to Time}

The variations of SPI and SPI ( $t$ ) of the two projects with time are given in Figure 7 and Figure 8 respectively. Although Project A had maintained a fairly uniform trend in terms of performance with respect to time in physical terms $(S P I(t))$, both the projects showed a more or less same degree of performance when considered overall.

However, Project B had outperformed Project A for majority of the time. This might have been due to the delays resulted from the variations that occurred in Project A.

It can also be seen that for Project B, from February 2019 to May 2019, as SPI increased, CPI decreased. This might be due to less efficient material use, higher labour and overhead costs in working overtime to catch up the work.

\subsection{Uses and Limitations}

The performance intervals developed can be used to evaluate and understand cost and time predictability of Sri Lankan building construction projects on a monthly or bi-weekly basis. However, further analysis of individual cost components needs to be done. Also, the performance intervals are based on the premise that the current average levels of performance among the 'recognized leaders' in the industry are the expected levels by the parties involved.

Since the number of data points used to establish the performance intervals was relatively less, it is questionable whether they are sufficiently representative. Therefore, it is recommended to collect data from a higher number and a more representative set of projects to define the performance intervals more accurately in future research. 


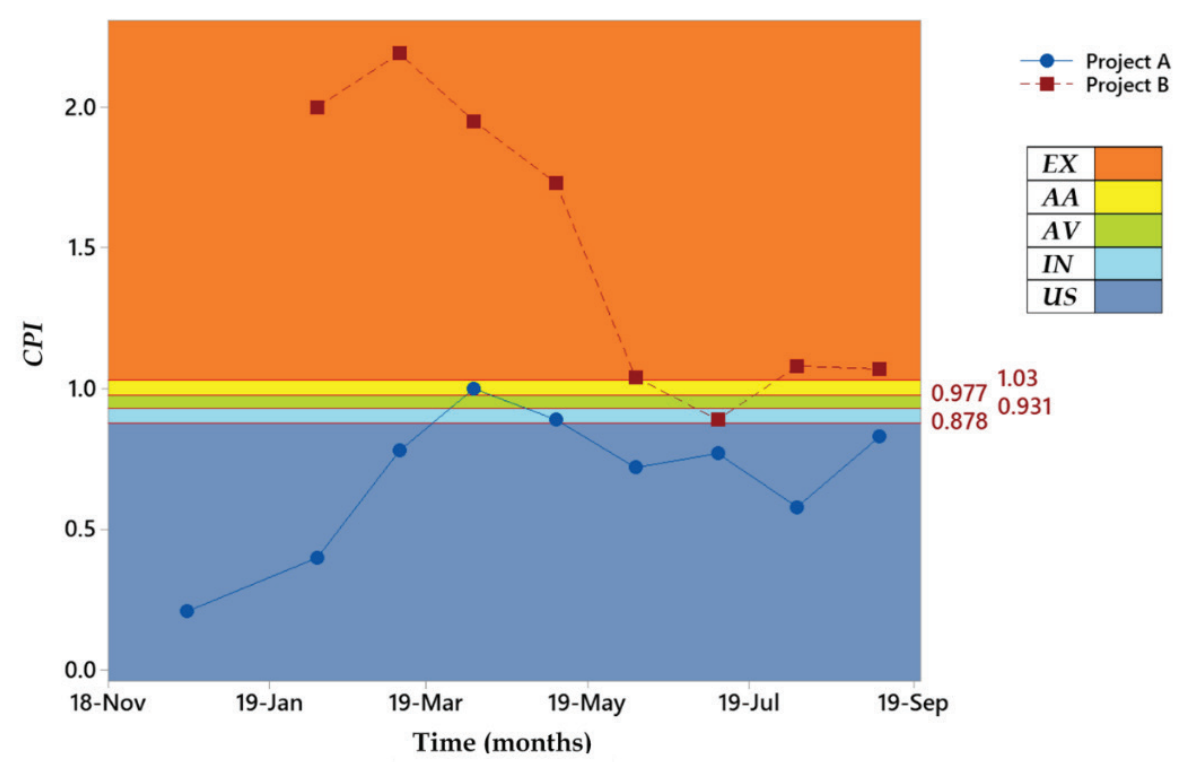

Figure 6 - Variation of CPI with Time

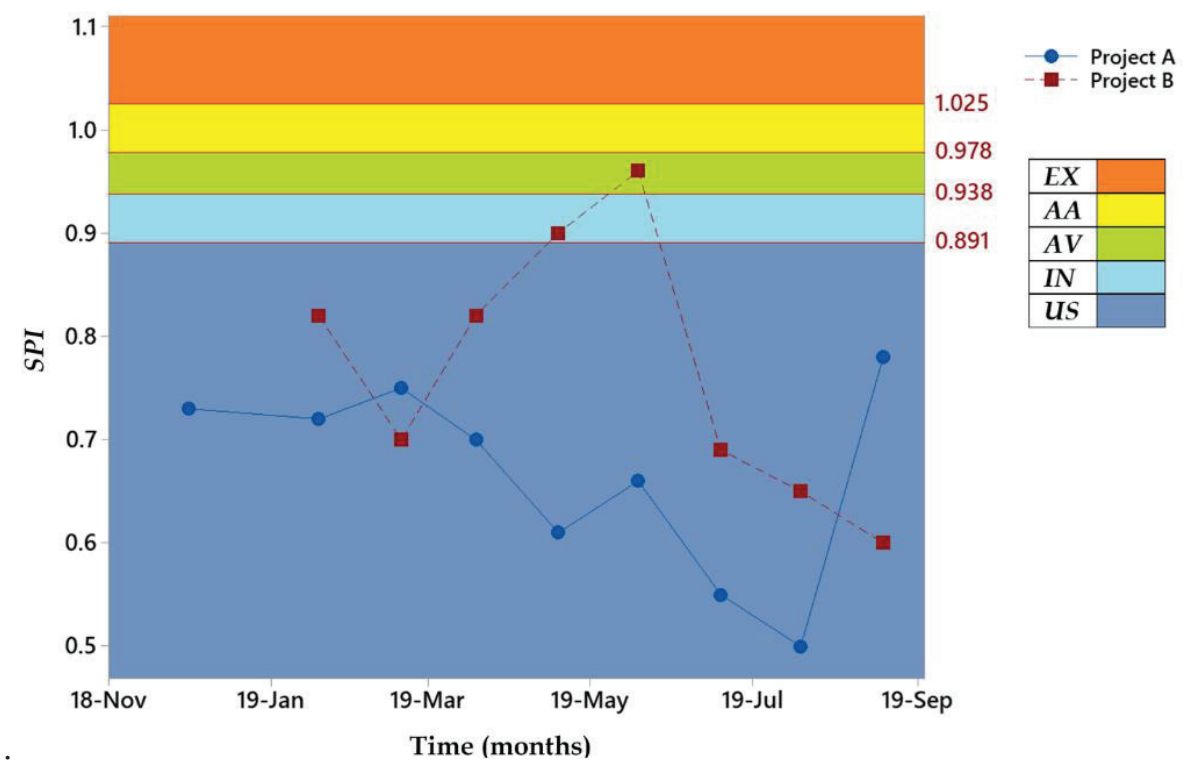

Figure 7 - Variation of SPI with Time

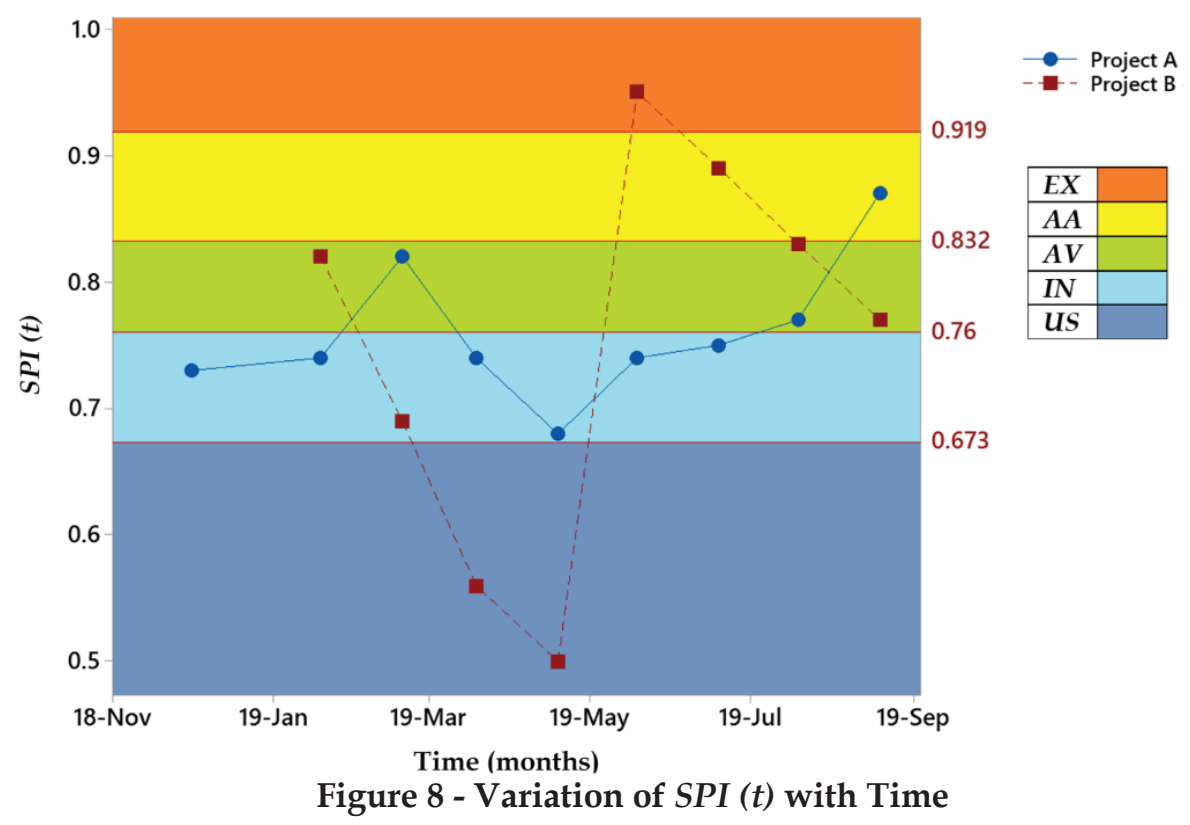




\section{Conclusions and Recommendations}

This study, through an extensive literature review, identified different indicators used to measure cost and time performance and found that the indicators based on earned value management are the most suitable. Also, the collection of data of twelve projects enabled benchmarks and performance intervals to be set. In addition, the application of the indicators to two ongoing projects helped to understand the performance related issues present.

However, the coverage of sample data required for a general conclusion was inadequate. Therefore, it is recommended to collect data from a higher number and a more representative set of projects to define the performance intervals more accurately in future research. Moreover, the scope can be expanded to other types of projects.

\section{Acknowledgement}

The authors wish to acknowledge the support given by the management and the officers of International Construction Consortium (Pvt) Ltd, Sathuta Builders (Pvt) Ltd and Access Engineering PLC in collecting valuable data for this study.

\section{References}

1. A Guide to the Project Management Body of Knowledge, 5th ed. PA, USA: Project Manage. Inst., 2013.

2. Department of Census and Statistics, National Accounts Estimates of Sri Lanka. Colombo, Sri Lanka: Ministry of National Policies and Economic Affairs, 2018.

3. Rathnayake, A. \& Ranasinghe, M., "A KPI Based Performance Measurement Framework for Sri Lankan Construction Projects," 2020 Moratuwa Engineering Research Conference (MERCon), Moratuwa, Sri Lanka, 2020, pp. 348-353, doi: 10.1109/MERCon50084.2020.9185304.

4. Hadiwattege, C., "Factors Affecting Construction Costs in Sri Lanka," Aug. 2014.

5. Jayalath, D. S. K. U., "The Most Significant Causes of Delay in Construction in Sri Lanka," M.S. thesis, Dept. Building Econ., Moratuwa Univ., Moratuwa, Sri Lanka, 2010.

6. Niven, P. R., Balanced Scorecard Step-by-Step: Maximizing Performance and Maintaining Results. New York: John Wiley \& Sons, Inc., 2002.
7. Gregory, M., Neely, A., \& Platts, K., "Performance Measurement System Design: A Literature Review and Research Agenda," Int. J. Oper. Prod. Manag., vol. 15, no. 4, pp. 80-116, Apr. 1995, doi: 10.1108/01443579510083622.

8. Bubshait, A. A., \& Almohawis, S. A., "Evaluating the General Conditions of a Construction Contract," Int. J. Proj. Manag., vol. 12, no. 3, pp. 133-136, 1994.

9. Chan, A. P. C., \& Chan, A. P. L., "Key Performance Indicators for Measuring Construction Success," Benchmarking Int. J., Apr. 2004, doi: 10.1108/14635770410532624.

10. Yeong, C. M., "Time and Cost Performance of Building Contracts in Australia and Malaysia," 1994.

11. Luu, V. T., Kim, S. Y., \& Huynh, T. A., "Improving Project Management Performance of Large Contractors using Benchmarking Approach," Int. J. Proj. Manag., vol. 26, no. 7, pp. 758-769, Oct. 2008, doi: 10.1016/j.ijproman.2007.10.002.

12. Hatush, Z. \& Skitmore, M., "Evaluating Contractor Prequalification Data: Selection Criteria and Project Success Factors," Constr. Manag. Econ., vol. 15, no. 2, pp. 129-147, 1997.

13. Alvarado, C. M., Silverman, R. P., \& Wilson, D. S., "Assessing the Performance of Construction Projects: Implementing Earned Value Management at the General Services Administration," J. Facil. Manag., vol. 3, no. 1, pp. 92-105, Jan. 2004, doi: $10.1108 / 14725960510808419$.

14. Lipke, W., "Schedule is Different," Meas. News, vol. 31, no. 4, pp. 31-34, 2003.

15. Rathnayake, A., "Performance Measurement Tools for Sri Lankan Contractors," B.S. Thesis, University of Moratuwa, Moratuwa, 2020.

16. Camp, R. C., "Benchmarking: the Search for Industry Best Practices that Lead to Superior Performance," 1989.

17. Plemmons, J. K.,\& Bell, L. C., “Measuring and Benchmarking Materials Management Effectiveness," AACE Int. Trans., vol. 1994, p. MAT2. 1, 1994.

18. Hudson, D. N., "Benchmarking Construction Project Execution," University of Texas at Austin, 1997.

19. El-Mashaleh, M. S., Minchin, R. E., \& O'Brien, W. J., "Management of Construction Firm Performance Using Benchmarking," J. Manag. 
Eng., vol. 23, no. 1, pp. 10-17, Jan. 2007, doi: 10.1061/(ASCE)0742-597X(2007)23:1(10).

20. "National Registration and Grading Scheme for Construction Contractors." The Construction Industry Development Authority. http://www.cida.gov.lk/sub_pgs/con_registrati on.html (accessed Dec. 2, 2019)

21. Chang, A. S. T., "Defining Cost/Schedule Performance Indices and Their Ranges for Design Projects," J. Manag. Eng., vol. 17, no. 2, pp. 122130, 2001.

22. Ryan, T. P., Modern Engineering Statistics. John Wiley \& Sons, New Jersey, 2007.

23. Lipke, W., Zwikael, O., Henderson, K., \& Anbari, F. "Prediction of Project Outcome: The Application of Statistical Methods to Earned Value Management and Earned Schedule Performance Indexes," Int. J. Proj. Manag., vol. 27, no. 4, pp. 400-407, 2009. 